\title{
Artesanías em palha de tucumã e memória: tecendo territorialidade e relações socioculturais
}

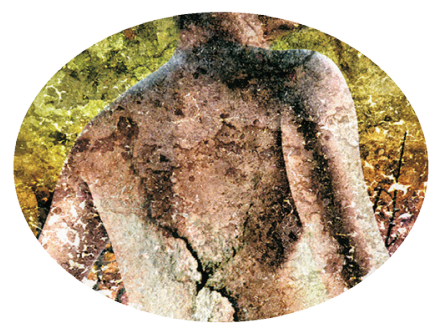

Thais Helena Medeiros ${ }^{*}$

\section{Resumo}

O estudo relata algumas reflexões sobre a memória coletiva e a mobilidade territorial das redes socioculturais de artesãos de objetos em palha de tucumã, habitantes das margens do rio Arapiuns, município de Santarém, Estado do Pará. As mediações dialogam entre as teorias selecionadas e o trabalho de campo distinguindo sociedades amazônicas em movimentação, geografando espaços artesanais em suas ressignificações culturais, percorrendo novas experiências. São contribuições para uma análise de maior amplitude no âmbito do projeto de pesquisa do Mestrado em Sociologia, na Universidade Federal do Amazonas (PPGS/Ufam). A pesquisa de campo foi organizada em um enfoque interativo nas ciências sociais a partir do referencial teórico interpretativo no fundamento etnográfico.

Palavras-chaves: Artesãos; memória coletiva; mobilidade territorial; redes socioculturais; rio Arapiuns

\begin{abstract}
The study reports some reflections on collective memory and territorial mobility of socio-cultural networks of artisans objects straw tucumã inhabitants of the banks of the river Arapiuns, Santarém, Pará State. Mediations dialogue between selected theories and fieldwork distinguishing Amazonian societies in movement, geografando space craft in their cultural significations, covering

* Mestre em sociologia pelo Programa de Pós-Graduação em Sociologia - PPGS da Universidade Federal do Amazonas - UFAM. E-mail: thais.ouricoamazonia@gmail.com
\end{abstract}


new experiences. Are contributions to an analysis of greater amplitude in the research project of the Master in Sociology at the Federal University of Amazonas (PPGS/UFAM). The fieldwork was organized in a interactive approach in social sciences from the theoretical foundation in interpretive ethnography.

Keywords: Artisans; collective memory; Territorial mobility networks sociocultural; river Arapiuns

\section{Introdução}

O pai dos meus filhos foi o tucumãnzeiro.

Eu baixava para a cidade, eram 10, 15 cestões.

Dona Alzira Lopes, 64 anos, artesã de palha de tucumã e moradora de Vila Brasil, família de Peré, Lago Grande

$\mathrm{Na}$ confluência das águas pretas e claras, no município de Santarém, é mantida a prática do trançado artesanal de palha de tucumã, elaborado principalmente por artesãs/ãos do rio Arapiuns ao encontro com o rio Tapajós. No inverno, as matas ciliares se cobrem de água formando os igapós. No verão, ficam delineadas pelo batom branco exibido das praias de areias alvas. Desnudadas pela vista de sua calha estreita espraiam perfeitos esconderijos (MEDEIROS, 2012). Assim o eram, pois, mais distante da confluência política e colonizadora da Corte Portuguesa e Igreja Católica, para onde muitos dos povos indígenas dessa mesorregião acudiram à época do movimento cabano em bancarrota pelas forças da situação (DANIEL, 2004; GT COBRAGRANDE, 2009; CEAPS et. al., 2011). Belezas naturais, esconderijo e uma avantajada sociobiodiversidade devem ter contribuído para os processos migratórios na formação social e cultural daquelas paragens (BENCHIMOL, 2009; MACHADO, 2002; HÉBETTE e MOREIRA, 2004; CASTRO, 2008).

Diferente da paisagem de várzea do Lago Grande do Curuai, caracterizado pelas águas esbranquiçadas do Amazonas, mas de igual abrangência das águas grandes e vazantes. Atribuo a essa dinâmica ambiental um dos fatores que influenciam expressivamente no modo de vida das pessoas. Uma característica da frequente mobilidade de gente e de povoados. Bem como influenciam 
na forma como se apropriam do espaço, como manifestam a subsistência e especialmente como concebem o mundo (ALENCAR, 2007).

As análises dos nexos que assumem as artesanias, ${ }^{1}$ neste trabalho, tecem uma reflexão em torno da memória coletiva (HALBWACHS, 2006; ALENCAR, 2007; LITTLE, 2012) em recordações pelos enunciadores e elaboradores das cestarias nas formações de (novos) lugares parentais que, por sua vez, estão estabelecidas nas margens do rio Arapiuns. Entendo que rememorar é parte integrante "das redes de solidariedades múltiplas em que estamos envolvidos. Nada escapa à trama sincrônica da existência social atual". Assim, na combinação de muitas e diferenciadas coisas emergem o que nomeamos de lembranças transcritas em uma linguagem que me permite interpretar a realidade que emerge no agora, aqui no Arapiuns (HALBWACHS, 2006: 12).

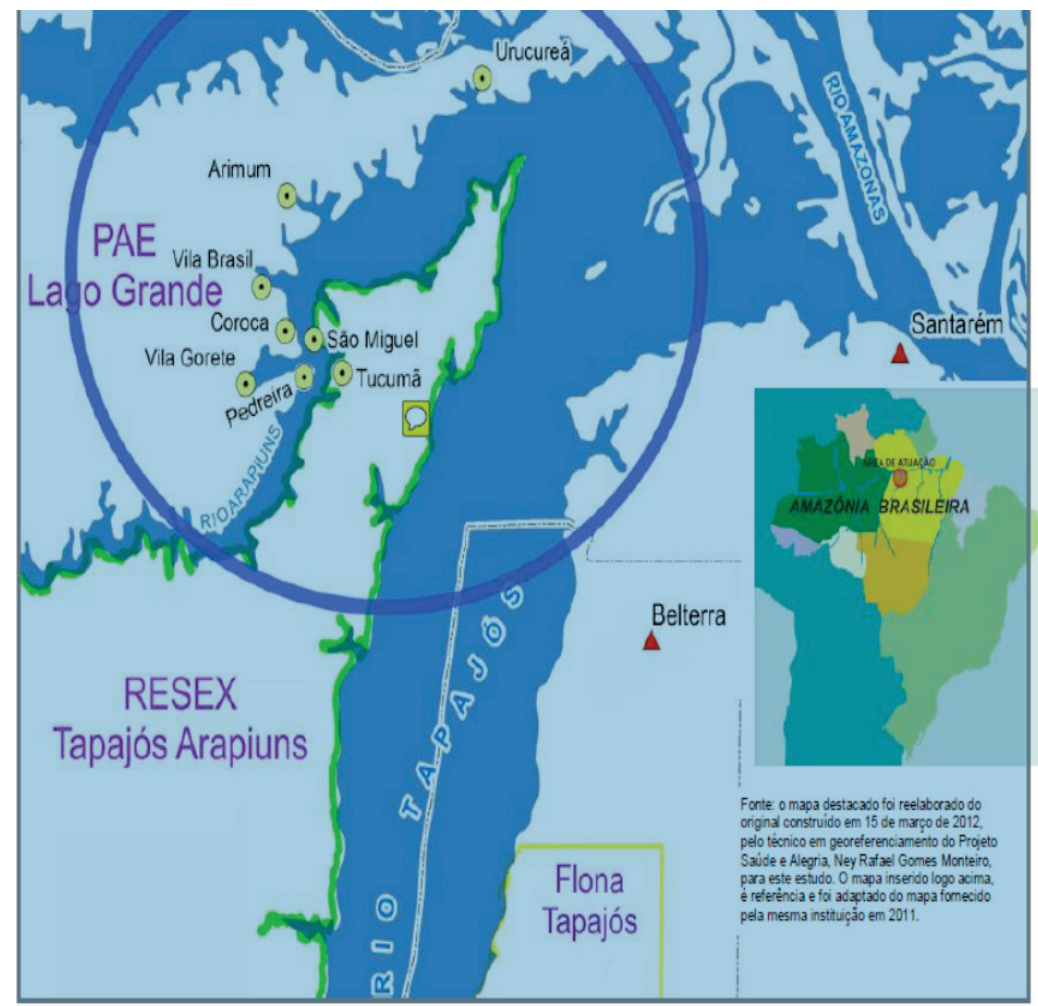

Figura 1 - Área da Resex Tapajós-Arapium e o locus da pesquisa.

Fonte: Adaptado do mapa do PSA, 2011. 
Hoje em dia, naquela área onde estão espargidas as localidades e proximidades de Vila Gorete, Vila Brasil, Arimum e Urucureá, dentro do Projeto de Assentamento Agroextrativista Lago Grande (Paelg); e São Miguel, na Reserva Extrativista Tapajós Arapiuns (Resex Tapajós-Arapiun); expõem uma paisagem sociocultural escolhendo a cestaria como representante, recortando o mundo social, cultural, econômico florestal daqueles grupos (Figura 1). Percorrendo o que digo ser o caminho das artesanías da palha de tucumã, deparei com uma mobilidade estabelecendo lugares em formação favorecidos por fatores advindos e acumulados por uma narrativa social rarefeita de modernização (NEDERVEEN PIETERSE, 1993). Fluxos crescentes de modernidade personificados no agora pelo encontro com o design está delineando a realidade, trazendo em seu bojo os movimentos da arte e vanguarda, do consumo e mercado (MANZINI, 2008; KRUCKEN, 2009; WILLIANS, 2011). O tecume em palha de tucumã desponta como um balizador, uma tradição na superação do externo que massifica nosso modo de vida, possibilitando o ressurgimento de identidades grupais ou étnicas (BARTH, 1998; THOMSON, 2002). E vem acoplada a um outro balizador: a conservação dos recursos naturais como meio que possibilitem processos de expansão "das liberdades humanas" (VEIGA, 2010: 37).

Assim, o estudo aqui desenvolvido abre um debate interno das ideias que fundamentam a compreensão dos processos de ressignificação das artesanías em palha de tucumã e suas redes de sociabilidade e comércio da floresta tecendo a vida e a trama da história (ALENCAR, 2010; 2002). Mais específico sobre os processos e estratégias da memória coletiva construída a partir da mobilidade e (re)territorialidades dos grupos familiares, onde tecedoras e tecedores elaboram objetos artesanais. Argumentações integrantes do apoderamento das discussões teóricas associadas ao trabalho de campo do projeto de pesquisa apresentado ao Programa de Pós-Graduação em Sociologia da Universidade Federal do Amazonas (Ufam).

Como parte da dominação intelectual interna, as discussões estão dispersas em alguns artigos que tenho produzido para eventos acadêmicos friccionados pela orientação metodológica organizada em um enfoque interativo em ciências sociais a partir do referencial teórico interpretativo. O trabalho de campo analisado fez uso de conversas e entrevistas espontâneas utilizando temas geradores ancorados nos fundamento freirianos (1996) 
listados previamente e observação participante.

Empenhei a oralidade como um método, mas também como um recurso de transmissão de saberes advindos das experiências e construções sociais, resguardados na memória viva daqueles que vivenciaram a experiência ou mesmo que já tenham sido narradas pelas gerações anteriores e "podem sustentar elementos de diferença cultural muitas gerações depois do período inicial de migração" (THOMSON, 2002: 1). Os registros de campo foram realizados em caderno, fotografias e pequenos filmes. Em alguns momentos fiz uso de gravações no intuito de segurar para as recordações na construção da narrativa, apesar de não ser a intenção transcrever todo o conteúdo.

Em busca da compreensão dos processos que regem as relações socioculturais dos grupos das artesanías em palha de tucumã, ancorei-me em Geertz (1989) quando nos ensina que a etnografia é uma atividade interpretativa numa descrição densa. Nesse sentido, é voltada à busca das significações, suas estruturas e produção de sentidos. Assim, como Cardoso de Oliveira (2006) me convida a olhar, ouvir e escrever, James Clifford (1998) me propõe a escrita etnográfica na qualidade de construção de empreendimentos textuais numa historicidade e cultura própria.

\title{
Memórias que geografam territórios simbólicos e espaciais
}

\author{
O tempo gira e descobrem coisas (...). \\ No passado não sabiam, pronto... parece que acordaram. \\ Dona Nair Santos Lopes, Vila Gorete, \\ família de Coroca vinda do Lago Grande
}

As famílias dos grupos que tecem as artesanías movimentam-se de um lado para outro do rio e suas enseadas em trajetos que se aproximam aos processos históricos de colonização como pressões externas políticas, econômicas ou mesmo sociais e religiosas. Em sua maioria, deslocaramse do Lago Grande do Curuai, várzea do Amazonas, para o Arapiuns em busca de ocupação econômica e matrimonial, refixando-se em novos lugares. Analiso que houve movimento do Arapiuns para o Lago Grande, mas com um fluxo bem menor a despeito da intensa mobilidade do sentido contrário. Nenhuma da/s artesãs/ãos ouvidas relatou um caso de retorno permanente 
para o Lago Grande. Aqueles que aqui vivem como patriarcas ou matriarcas de famílias numerosas tiveram, em seus bisavós e avós ou pais, a migração de lá para cá. O extrativismo mais lembrado foi o das castanheiras pelos famosos castanhais em Alenquer e Monte Alegre, como o Mamiá e Cachoeirinha. Mas também recordaram da madeira e da seringueira, assim como da ocupação de vaqueiros na várzea, entre outros lugares (GALÚCIO, 2007). O ponto final foi o Arapiuns e seu extrativismo insipiente em proteínas animais. Ali, retornavam e encontravam suas parceiras num rearranjo familiar.

Mais atrás no tempo, os encontros se davam em farinhadas e tapiocadas nas festas de santo em eventos interlocalidades. Hoje em dia, as atividades sociais são os torneios dos times de futebol com os bailes. As artesãs apontaram lugares de festas como São Pedro, no Arapiuns; Lago da Praia, Gorete, Brasil; no Lago Grande do Curuai, Ajamurim; São José, na rodovia Translago (PA257). Há lugares que gozam de popularidade de bons torneios de futebol masculino e feminino, tem as festas animadas que começam pela manhã se estendendo noite adentro com mais de duas bandas tocando. Nesses bailes, ouve-se a música de gênero brega, onde os casais dançam entrelaçando seus corpos em um sincronismo rápido e efervescente.

$\mathrm{Na}$ busca das estratégias, ao rememorarem a "lembrança do passado e construir a memória da história do grupo e do lugar”, percorri a memória das velhas/os tecedeira/os, bem como os mais antigos que ainda vivem e se envolveram nas recordações do passado reconstruindo o presente. Aqueles mesmos que ainda "conservam fragmentos da história de formação do lugar e do grupo social” (CASTRO, 2007: 102). Ao lado daquelas memórias, os complementos das narrativas do que se marcou na memória de integrantes dos grupos atuais das artesanías nas localidades de Gorete, o Grupo Sacaí; em São Miguel, ArtePalha; Vila Brasil, Tamuarte; Arimum, Jararaca; e Urucureá, o TucumArte.

Seguindo os fundamentos teóricos de Halbwachs (1990), as memórias narradas aqui estão marcadas nas pessoas como fragmentos. Ao mexermos com as lembranças, avivamos as marcas deixadas em nossas mentes que se reconstroem ao se chocarem com as marcas das outras pessoas. $\mathrm{O}$ autor aponta que o passado não está marcado intacto na mente individual, por isso necessitamos do grupo na reconstrução do passado no presente. Edna Alencar (2007: 101) ajuda a desenvolver essa ideia ao apontar que "memória social é um 
processo coletivo, onde o grupo social desempenha um importante papel no processo de lembrar e de conservar a memória”. E complementa:

Portanto, é o grupo social que constrói e dá significado ao lugar, e cada grupo constrói sua identidade a partir dos vínculos de parentesco que unem as famílias entre si e estas com o lugar aberto pelos ancestrais. O pertencimento ao lugar e a um grupo de parentesco garante o acesso ao território e aos recursos naturais, e funciona como um mapa cognitivo que orienta as relações entre as pessoas e entre essas e o ambiente (ALENCAR, 2007: 98).

No encontro com as memórias da territorialidade que hoje está constituída no entremeio das relações socioculturais das elaboradoras/es, Januário Cardoso, 83 anos, sogro da artesã Rosalina de Sousa Castro (Rosa), de Vila Gorete, neto de Laura (ou Áurea), mãe da artesã dona Josefa Cardoso, 90 anos, ${ }^{2}$ e que compõe a raiz deste trabalho, contou-me sobre suas lembranças de parentescos, sobre as suas andanças - como seu Júlio Dias, de Vila Brasil, que também é da mesma geração e que rememorou comigo partes de sua vida - e sobre essas formas de casamentos. Ao longo do percurso, esses fatos foram lembrados pelas pessoas que, despertadas a recordarem suas vidas por meio de minha conversa, tendo a cestaria como gancho, estabeleciam os processos históricos de ocupação humana àqueles lugares que defino como focal difusor dos tecidos "miudinho, trançadinho, enroladinho, de miúdo" e suas variações do "olhinho" ou de "buraco". Bem como os momentos particulares de suas vidas que soam tão significativos no presente, remetendo "a um momento importante do desenvolvimento do seu grupo” (ALENCAR, 2010: 25).

"Quando já tava assim [...] rapazinho [...] comecei a trabalhá já por minha conta, comecei a andar, vagabundando [...] pude comprar uma coisa pra mim. De lá eu virei, mexi por aí [...] tinha essa coisa... da minha mulher ainda... morava lá num lugar chamado Nazário, uma colônia que tem aí pra cima [LG]. E aí, ela [...] viveu, namorou por aí, num noivo, num arranjo noivo, num quiseram casá com ela. Mas também foi [...] história dela porque quando ela tava curuminzinha ela [...] a finada minha avó chamou 
pra amostrar as filhas dela pra ela e ela também amostrou [...] a velha Jovina chamou as filhas pra juntá as filha dela pra outra velha. As duas velhas foram conversar. É. E aí, ela disse assim, a finada minha vó disse assim: olha essa, essa é a minha filha [...] a tia Josefa [...] é a caçula. A Gita tá madurinha e essa aqui já é velha, que era a mamãe. Ela disse: Por que velha? Porque já tem filho [...] aí ela disse [...] já tem filho [...] e o filho tá negando fogo (risos). Hum, é, e aí ela disse assim [...] eu vim falá com seu filho. Ah, coitado do meu filho [emocionado]. Não, quando já, meu filho já tá jito e a senhora já tá namorando com rapaz feito. Ela disse não [...] eu posso namorar quanto eu quiser, mas eu vou esperar ele se criar. E aí ficou assim. E olha, foi embora pra lá na terra dela, por lá viveu e eu, acabei me criando. Mamãe morreu, fiquei [...] meus avô, tio [emocionado] me criaram. Quando eu tava, viu, no ponto pra trabalhá, comecei a sair de uma parte pra outra. Escapei de morrer, mas não fui só de morrer. É. E assim foi. Depois eu fui trabalhar lá [...] pro [...] Surubim-Açu, por lá tive andando por lá. Lá arranjei uma cunhantã e vim filiá, casá isso comigo [...]. Eu ainda tava muito novo. Eu também fiquei um ano e depois vim, vim aí pra casa [...] aí eu falei: não eu vou [...] Aí, o cumpadre Bigode, pai dessa menina aí [apontando para a Edilair], tava também nesse trabalho. Nós viemos juntos de lá. E essazita, que foi minha mulher, era namorada dele, do cumpadre Bigode. É, nós era primo e irmão bem dizer, e nós [...] juntos, trabalhando. E aí, quando nós chegamo pra cá [...] ele foi lá pra banda dela. Que ela morava num lugar chamado Pilanzinho, bem pra aí. E eu morava na Pedreira. Aí, ele disse assim pra ela, pra Virginia. Ele disse assim pra ela: Vitor, tu sabes que o compadre Januário veio pedir licença pra o vovó, pra casá com uma mulher de Surubim-Açu? Ela respondeu assim pra ele: quê, ele casá? Ele vai é casá é comigo. E aí ele disse assim: quem é essa mulher? Ele é teu macho? Ela disse: não, não é não, pois ele vai sê! Pra podê criá ele direito. E aí, foi o tempo que [...] eu também vim de lá, já mais formado, eu tava com 18 ano de idade. E aí, por aí, nós topemos de novo [...] pra cá, pra li [...] ajustemos a amizade nós dois e aí casei com ela, com a Rita. E quando o cumpadre veio dela, dela da várzea, o irmão dela ainda quis brigar comigo por causa dela. O finado Zequinha. $\mathrm{E}$ 
o cumpadre tava lá, num tava nem ligando [Bigode é o agrado do Gregório]. E aí, eu disse: rapá, tu qué é brigá comigo por causa da tua irmã, tu queria tua irmão pra tị? Não, porque eu sabia que ela era comprometida com esse meu cunhado. Eu disse, era, mas ele não tava fazendo caso dela e eu tava precisado dessa mulher [risos]. Ela tá lá pra cima eu levei ela. Lá pra casa de um home lá, pra ela se curá. O homem era curador. Eu fui levá ela pra lá pra ela ela ficô. E eu vou buscá ela amanhã. Quando eu cheguei aqui eu vou butá ela perto de ti que é pra tu dá essas duas bufetadas nela que depois [...] vai apanhar de ti e tu vai apanhar de mim ou então eu de ti. Seja como for. É. E aí, tudo bem. Quando foi no outro dia cedo, eu fui me embora pra lá buscar ela. Chegando, eu disse: olha, Ritinha, vamo embora, borá que eu [...] nosso casamento vai dá em briga porque teu irmão vai te bordoá e já [...] ele experimentou, mas ele não teve coragem e agora tu vai vai apanhar dele. Tá, eu vou, não tenho medo dele. Quando cheguemo aí eu disse: Óia, tá aqui, sua muié pode [...] mas aí pode [...] Não, mas aí [...] aquilo porque [...] de besta. Não, não que eu quisesse borduá minha irmã. Então, a gente não promete o que não faz, né? E assim nós fiquemos, fiquei, eu fiquei com ela e fui o tempo que o meu cumpadre Gregário ajeitou essa Nair pra lá pra Coroca, pediu pros pai e aí deram pra ele e casou com ela. E foi o tempo que eles vieram pra cá pra essa comunidade [...] tava se formando, e aqui vieram limpá o lugar e fizeram a casa deles aí. E aí moraram [eram vizinhos, Gregório com Nair e Januário com Rita, lá na Vila Gorete]".

A/os narradoras/es), ao relembrarem, emocionam-se com a imagem de pessoas queridas que já não fazem mais parte de sua vida cotidiana por falecimento ou por habitarem em outros lugares. Ao falarmos sobre a tecedeira Nair Santos Lopes, da Gorete, 74 anos, a artesã Jósima Nunes, 88 anos, a dona Miloca, de São Miguel, por exemplo, deixou sobressair um lampejo de alegria ao recordar da amiga deixando a emoção fluir em sua face. Notei que os mais velhos raramente vão visitar seus amigos em outras localidades. Viajam muito para Santarém, onde se munem de suas aposentadorias. Os mais jovens costumam se encontrar nos torneios e festas. Ainda na conversa com Rosalina, a dona Rosa, falando sobre a vinda de seus padrinhos Nair e Gregório e de 
seus pais para a fundação de Vila Gorete:

Elas se agradaram, com certeza, da Vila Gorete e vieram morá pra cá. Igual o meu pai. O meu pai [Laurindo de Sousa] casou com minha mãe e morou pra cá. [...] Não, foi assim, ele contava que ele veio em comissão, andando com santo pra cá, pro Arapiuns, né? [...] Aí, eles se enamoraram pra cá, se gostaram. Naquele tempo era do pedir, mesmo pedi [Edilair diz 'pedi e já ficava']. Achou a mãe de dona Rosa que era daqui. A Maria Cardoso conhecida como Zarita. "Eles ainda eram parente, acho que meu avô era da família dos Cardoso.

Carregando na memória os elementos concedidos no presente da vida social, os fatos são projetados no passado que está sendo reinventado nas novas experiências narrativas que magicamente recompõe. Inspirada em Halbwachs (2006), marco ainda que as pessoas, ao enunciarem o passado pela memória, juntam as lembranças com que descrevem os fatos ou objetos, reconstituindo o passado pela coletividade rememorada. O caso das artesanías, por mais que seja reinventado neste presente, é somatória da memória coletiva, permanecendo em tradições pelos trançados nos grupos familiares onde está configurado a presença matriarcal da técnica. Não tendo como se prender a outros interesses, posto que convivem em um mesmo lugar, numa mesma territorialidade imanente de símbolos que os agreguem ao passado de gerações, acrescenta o autor que a memória "só a perdemos para reencontrá-las" na coletividade (2006: 36).

Por que migrarem da várzea, onde existe uma oferta mais abastada de proteínas animais para as ilhargas do Arapiuns onde, em tempos de cheia, o peixe foge pela água grande levando seu povo a depender do mercado de Santarém para a satisfação das necessidades alimentares? $\mathrm{Na}$ busca da ocupação econômica e matrimonial, seguem a traçar práticas inovadoras ao se confrontarem com transformações simbólicas e culturais partindo dos elementos da diversidade e diferenciação dos recursos naturais em seus lugares distintos. Os rios de água preta, como o Arapiuns, vivenciam uma ecologia diferente dos rios de água branca, em consequência do manejo ecológico sazonal e abrupto para curtos espaços, como é o intervalo de terra que compõe hoje o Paelg entre a várzea 
do Amazonas e a ilharga direita do Arapiuns (CEAPS, 2007; ISAAC, 2003; MACHADO et. al., 2001).

\begin{abstract}
Por que ela me falou assim, né? Que ela morava com a sogra dela, mas ela não se dava bem com a sogra dela. Porque ela não era muito daquelas pessoas que trabalha [...] A sogra dela era muito trabalhadora. Elas trabalhavam aqui prum sítio, de madrugada levantavam e faziam o que bebe [...] e ela não era acostumada. Ela era [...] isso ela me contou, né? E aí, ela procurou saber com o meu padrinho, que já era o marido dela, que ela não queria mais viver com a sogra porque ela era chateada (Rosalina de Sousa Castro, Vila Gorete).
\end{abstract}

A narradora aponta que viviam depois da ponta do Miripixi, "bem na entrada", ajudou a lembrança de dona Rosa o Sr. Januário, nascido em Pedreira, lugar de origem da parentagem de dona Josefa Cardoso para se fixar em São Miguel, bem em frente a Miripixi. Ela que é a criadora do teçume de "buraco" ou "olho" e tronco de partida para este estudo. Ele recordou que na interconectividade das movimentações das pessoas naquele território, tanto Anastácio e Miqué, pais de Nair e Conceição, artesãs mais idosas do grupo familiar de Coroca vieram do Lago Grande. Os pais de Miqué, que tinha o agrado de Mãe Velha, não conheciam o Arapiuns. Seu pai era pescador de pirarucu e fazendeiro de gado lá para o Lago Grande do Curuai. Foi aqui no Arapiuns que Nair Santos Lopes casou-se com Gregório Guimarães Lopes. Essas mesmas lembranças também foram recordadas pelas duas irmãs em nosso encontro para esta pesquisa.

Edilair, que é filha de Nair, nessa conversa, intercedeu que a família da mãe é muito grande, mas que até estar me acompanhando nesta pesquisa, tinha pouco conhecimento da cadeia geracional de seu parentesco. Em Santíssima Trindade, ela retoma a extensão neste presente dos conhecimentos geracionais a partir das recordações de dona Antônia dos Santos Castro e sua parentela que lá estava reunida na conversa, reiterando que agora é que está "dando conta da sua família".

O Arapiuns das artesanías em palha de tucumã vivencia um intenso sobe e desce de mercadorias e pessoas levando e trazendo coisas e ideias, 
concepções de mundo e modos de vida. Essa intensidade se assemelha a momentos de ruptura compartilhando com o que Koppytof (apud HANNERZ, 2012) chamou de interstício. Entendendo esses lugares sob tal égide, os espaços são fundidos a partir de símbolos capazes de criar fluxos globais por meio das artesanías, distinguindo sociedades amazônicas em movimentação, geografando e definindo socialmente espaços artesanais em suas ressignificações culturais e percorrendo novas experiências (ADAMS, 2006; JURANDIR, 1995; WAGLEY, 1988).

Para analisar as relações socioculturais traçadas pela elaboração das artesanías, também me aproximo das ideias de Little (2012), entendendo que os caminhos das famílias estão envoltos numa multiplicidade de eventos que caracterizam a mobilidade. A paisagem social está se refazendo na dinâmica dos movimentos incessantes, percorridos e vivenciados pelas pessoas nesse momento. Construindo o pensamento nesse sentido, aproximo-me do pensamento que descreveu Kopytoff nas análises de Hannerz (2012), onde "pequenos grupos de pessoas se encontram para formarem os princípios de uma nova sociedade" (HANNERZ, 1993: 22; KOPYTOFF, 2008).

Nas elucubrações dissertativas apresentadas aqui, antevejo as relações socioculturais em torno da cultura material que as artesanías em palha de tucumã é capaz de assinalar em marcos teóricos atrelados ao debate do (re) territorialização contínua que proporciona a mobilidade social (LITTLE, 2012). Almeida (2008: 32) interpreta que as identidades coletivas são "redefinidas situacionalmente numa mobilização continuada, assinalando que as unidades sociais em jogo podem ser interpretadas como unidades de mobilização". Posso atribuir ao tucumãzeiro e suas artesanías uma fonte de demarcação simbólica que identifica grupos socialmente dispersos em um território. É uma das tantas escolhas que limitam a condição de estar no grupo, de pertencer àquele grupo (HANNERZ, 2012; NEDERVEEN PIETERSEN, 1993). Essa identificação corrobora para a remodelagem dos territórios pela circulação das pessoas nos espaços. O que na Amazônia está diretamente relacionada à colonização, fluxos econômicos ou periodicidades, a abertura de estradas e as implantações dos assentamentos de ocupação estatais e privados (HÉBETTE e MOREIRA, 2004; CASTRO, 2008; ALMEIDA, 2008) advindos da modernização do Estado brasileiro.

A vasta área de floresta, entremeada de campos naturais, outros 
rios, igarapés, furos e paranás do Arapiuns está plenamente povoada em agrupamentos de casas, nas parentagens ou vilas ligadas às sedes municipais de pequenos e médios portes. A mobilização no eixo urbano-rural produz espaços públicos que estruturam os vínculos sociais. A ruptura em curso com as práticas sociais preexistentes resultantes de transformações nas relações interculturais passam das relações de produção para a análise da produção das relações (CASTRO, 2008).

Mediados por experiências desveladas na permanência de oposições clássicas entre o velho e o novo, o tradicional e o atual, controvertido, conflituoso e contraditório, a globalização é um fomentador e edificador de lugares onde as culturas se encontram, misturam-se, recombinam-se. Um movimento contínuo de grupos movidos pelos fluxos e mobilizações territoriais compondo relações socioculturais, ressignificando imaginário simbólico e ressurgindo identidades (HANNERZ, 2012; BARTH, 1998; GARCIA CANCLINI, 2006).

As lembranças das artesãs vão construindo a história. Dona Antônia dos Santos Castro, conhecida pelo agrado de "Dondon", 74 anos, é filha de Celina dos Santos e Adelino Manoel dos Santos, foram os primeiros fundadores do lugar que hoje habita a parentagem descendente. Vindos da colônia chamada Patuça, que hoje é São Paulo, Lago Grande do Curuai, quando aqui chegaram só tinha a localidade de Bacabal, hoje Gorete, e o Retiro do outro lado, onde hoje é Pedreira. Na conversa em roda grande das tecedeiras filhas, netas pequenas, noras e parentas, ela me contou que vieram para cá porque se agradaram do lugar numa visita de reconhecimento do patriarca que depois trouxe a mulher e dona Antônia com 15 das de nascida. Notei como é forte sua presença na família deixando-me entrever um matriarcado.

Assim identifiquei nas demais famílias das tecedeiras. Em Arimum, o Lugar Velho foi erguido pela família de Júlio Ferreira, o patriarca das artesãs/ aos do Grupo Jararaca. Quem rememorou as histórias dessa parentagem foi sua cunhada Zenaide, contando-me que vieram de uma "colônia velha" chamada Muruí, entre Arapiuns e Lago Grande do Curuai. Maria Viana, a "Tapuia", teve sete filhos/as, era parteira e como quase todas as mulheres de sua geração, bem como a de suas filhas, plantava o próprio fumo e o fumava no cachimbo de barro ou mesmo de tucumã. Esse detalhe foi observado pelos expedicionistas e naturalistas, visível na literatura e nos estudos científicos dos 
que deslizaram no rio Amazonas entre os séculos 17, 18 e 19 (AGASSIZ \& AGASSIZ, 1975; BATES, 1979; INGLÊS DE SOUSA 1968; DANIEL, 2004; JURANDIR, 1995).

Dessa fusão mudam-se objetos de uso cotidiano imbuídos em novos conceitos experimentados na prática por meio das noções de sociobiodiversidade $^{3}$ (LIMA e POZZOBON, 2005; KRUCKEN, 2009). A extensão, como aponta Nederveen Pieterse (1993), é sua condição se expondo sob a noção da globalização. $\mathrm{Na}$ problematização do desenvolvimento ocidental e seus múltiplos caminhos da modernização, segue aquele mundo marcando uma maneira de ser, interagindo culturas e intensificando a mobilidade, deslocando imaginários, seus símbolos e geografando territórios (NEDERVEEN PIETERSE, 1993; BUARQUE DE HOLLANDA \& RIBEIRO, 2011). Alistair Thomson enxerga esse processo como "a passagem física da migração de um lugar para outro como apenas um evento em uma experiência migratória que abarca velhos e novos mundos e que continua por toda a vida do migrante e pelas gerações subsequentes" (2002: 1).

$\mathrm{Na}$ mobilidade territorial em que estão envolvidas as artesãs(aos), o lugar das artesanías compõem o espaço numa teia de aglomerados com práticas econômicas de autoprodução e de autoconsumo conectados em uma rede social e de comércio na floresta. Nesse sentido, é usual encontrar casas nas comunidades em que os cômodos frontais para a rua são convertidos em tabernas, no mercado de bens básicos articulados com os centros mercantis dos municípios como Santarém e Juruti (LEROY, 2012).

A intensificação da mobilidade agora parte dessas localidades para os centros urbanos mais próximos como são Santarém e Manaus. Castro (2008) insere suas argumentações no sentido cidade-interior apostando na realidade amazônica multiétnica e multilinguística. Dessa forma, discorre sobre a "necessidade de compreender o que são essas cidades" sobre a "possibilidade de entendimento desse universo incomum às teorias convencionais sobre o urbano e a urbanização”. Postula que dessa prática é possível “captar a natureza de suas redes e as territorialidades em jogo na sua relação com o território de floresta tropical"' (p. 16-17).

Investigando as sociedades amazônicas e sua realidade como um espaço multifacetado (ADAMS, 2006; SCHWEICKARDT, 2010), o fenômeno da mobilidade vem corroborar com a construção de uma "malha tipicamente 
rural de aglomerados dos mais variados tamanhos e em diversas escalas". Em harmonia com as ideias de Hébette e Moreira (2004), os povos geografam a construção do espaço rural edificado como uma "nova ruralidade", num redesenho de paisagens onde se privilegia o sentido interior-cidade, relevando a importância das atividades de cunho agroecológicos. Apesar de esses autores tratarem a migração pela ótica de fronteiras agromineral, ao contrário de Castro (2008), que enfatiza a urbanização da Amazônia, tratam a migração como “processo concomitante de 'ruralização' da Amazônia, isto é, o processo de construção do espaço rural” (p. 49-50).

As observações me levaram a interpretar que, mesmo insipiente, jovens retornam das cidades para as suas localidades. A competição acirrada e a carência educacional que oportunizam a entrada no mercado de trabalho os remeteram de volta. Nesse sentido, eles inserem que podem apoiar os processos educacionais de jovens e adultos menos complexos e cuidarem de seus pais já envelhecidos, porém detentores de uma renda mensal que é a aposentadoria.

Nesse processo cultural móvel entre a cidade e o campo, entre a modernidade e a vida pós-industrial, trançar cestos nos remete a uma das expressões técnicas e culturais imemoriais na história da humanidade. Encontrada por todos os continentes onde os povos aborígenes deixaram suas marcas, hoje em dia é utilizada tanto nos espaços interioranos no manejo dos recursos naturais e para a lida doméstica quanto nas cidades, em ambientes decorativos bem como artísticos pela beleza plástica (VELTHEN, 1998). Uma cesta num mercado urbano contemporâneo traduz simbolicamente o consumo sustentável de florestas produtivas manejadas (reuso, reciclo e redução de resíduos sólidos), a distinção étnica e equidade socioambiental.

O estudo da cultura material nas relações da produção e consumo pela lente das artesanías pode ajudar a entender essa complexidade na área de abrangência onde se nota a relação progressiva entre e o tradicional e o pósindustrial. Interpretando esse realce, é possível pensar que as comunidades pulam processos e rompendo os padrões, movem-se do estágio entre o tradicional e o moderno para o pós-industrial. Isso se justifica se olharmos a densidade demográfica crescente, a entrada dos meios de comunicação como a televisão, pela chegada da energia elétrica vinda dos motores movidos a combustíveis fósseis de Juruti, via mineradora Alcoa. Em algumas localidades da área, mais acesso a redes de telefonia móvel 3G, onde os jovens se conectam 
com o mundo (CEAPS et. al., 2011; 2008).

O crescente número de barcos de linhas para atender a demanda das pessoas em dependência do mercado de Santarém, percebe-se o que diria Kopytoff (2008: 99), uma certa mercantilização da vida social como uma característica da tecnologia que troca "que, historicamente, se associou ao capitalismo e que criou margens dramaticamente ampliadas para a máxima mercantilização possível".

A escolha das cestarias em palha de tucumã reflete uma associação entre a disponibilidade dos recursos naturais pelo manejo sem complexidade da palheira e a carga simbólica com que os povos na floresta tropical manipulam as fibras, talas e palhas (SHANLEY \& MEDINA, 2005). Parto do princípio de que o encontro entre técnicas de trançados com o curuá, bacaba, buriti, caranã, babaçu, arumã ou ambé ${ }^{4}$ que permanecem na memória coletiva e o manejo da palheira deve ter contribuído para a profusão das artesanías, distinguindo elementos culturais na formação de novos lugares. Bem como, e principalmente, pela condição artesanal exibida pela habilidade e criatividade das mãos que tecem a palha, deixaram-se notar pela memória dos contemporâneos.

Os mesmos espaços são demarcados pela elaboração da cestaria em palha de tucumã que recordados, refixam dinâmicas socioculturais e ambientais que não podem nem poderiam habitar fisicamente (LITTLE, 2012). Tem como traços comuns erigirem de núcleos familiares lembrados pelas práticas de tecer palha, talas, fibras, enviras, entrecascas, talas - que tramadas, trançadas, tecidas, entalhadas, incisadas, furadas e fiadas, cozidas em pigmentos vegetais elaboram objetos culturais (GONÇALVES, 2007). Espaço onde os grupos garantem aos seus membros direitos estáveis de acesso, de uso e de controle sobre os recursos e sua disponibilidade no tempo, assegurando a reprodução da existência e ressurgimento de identidades. Arena onde se situam as contradições entre Estado e sociedade civil, das práticas coletivas de inclusão social como pelas experiências espaciais e temporais em que os grupos significam o território (CASTRO, 1998; SCHWEICKARDT, 2010; ESTERCI \& SCHWEICKARDT, 2010; LITTLE, 2012; HÉBETTE \& MOREIRA, 2004).

Diante dessa paisagem híbrida, como híbridos com passado e ressignificando no presente, estabelecem uma resistência coletiva. A memória é 
posta em destaque para relembrar o passado transcendendo fronteiras comuns e se reconstruindo a partir desse processo. A compreensão da mobilidade territorial dos grupos familiares das/os artesãs/ãos carregando as práticas em seus múltiplos sentidos, cruzam com outras práticas numa reterritorialidade como constado no campo, numa hibridização cultural (LITTLE, 2012; GARCIA CANCLINI, 2006, HANNERZ, 1997).

As rememorações nos levam ao tempo em que, ao "se agradarem" pelas paragens, construíram lugares como o Aratapi, a Trindade, o São Marcos e o próprio Lugar Velho. Eles que hoje se recriam nas elaborações carregando na memória significados simbólicos e culturais expressados pela cestaria (LITTLE, 2012).

Técnicas nascidas não muito distantes desses lugares são carregadas na memória e fixadas por outras matérias-primas demandadas pela existência dos recursos naturais disponíveis. Nesse sentido, os lugares se fundiram com as demandas diferenciadas dos recursos naturais, onde se refixam no movimento cultural. Assim, realizam novas experiências de espaço e tempo utilizando a memória para se apoderar do que se deixou para trás. Nas conversas realizadas, não ouvi caso de retorno para o Lago Grande ou o Maró (LITTLE, 2012). Nesses lugares, onde as culturas se encontram, os agentes e produtos se misturam num movimento contínuo de "cambiantes habitats de significados" (HANNERZ, 1997: 10). Criam-se, dessa forma, fluxos das artesanais e na interação entre o local e o global, denotando uma "paisagem conceitual interdisciplinar" específica (HANNERZ, 1997: 10).

As cestarias elaboradas foram se mesclando aos intragrupos de parentagem que resguardam na memória coletiva traços culturais reforçando a vivência na floresta tropical. Elas estabeleceram conectividades com outros centros, expandido pelo crescimento do número de pessoas e sua mobilidade. Olhando pela imagem de uma imagem de satélite, por exemplo, ter-se-á, a olhos nus, a intensa urbanicidade que está preenchendo as ilhargas do Arapiuns, a norte o PAI Lago Grande, e a sudoeste a Resex Extrativista Tapajós-Arapiuns. E a arte de trançar a palha, de pigmentar com plantas do mato e domesticadas, de objetos culturais tão conhecidos na lida doméstica é uma das coisas escolhidas a permanecer diferenciada nesse encontro, não se permite cingir tão rapidamente numa resistência (HANNERZ, 1997).

A fusão de conhecimentos locais apreendida nos processos de 
espacialização do tempo nos territórios encontrados e escolhidos para se fixarem, mostram uma cultura impondo coisas e relações sociais "coletivamente compartilhadas ao mundo que, em termos objetivos, é inteiramente heterogêneo e contém uma gama de coisas singulares" (KOPYTOFF, 2008: 96). Acoplando a esta última característica da ideia de Arjun Appadurai (2008: 17), tem-se uma imagem social, onde "os significados estão inscritos em suas formas, seus usos, suas trajetórias":

Somente pela análise destas trajetórias podemos interpretar as transações e os cálculos humanos que dão vida às coisas. Assim, embora de um ponto de vista teórico, atores humanos codifiquem as coisas por meio de significações, de um ponto de vista metodológico são as coisas em movimento que elucidam seu contexto humano e social (APPADURAI, 2008: 17).

Respaldada em Godelier na entrevista concedida a Buarque de Hollanda e Ribeiro (2011), enxergo as artesanías envoltas em símbolos que constituem o imaginário na escolha para apoiarem as novas demandas econômicas e ambientais em suas vidas como difusoras/es do mundo e para o mundo que as/os rodeiam:

\footnotetext{
Para que o imaginário seja a produção de sentido, de significações para a existência das pessoas e essa produção se dê no pensamento, claro, mas para que isto seja socializado - social é necessário que ele passe por símbolos. Os símbolos não são, portanto, o fundamento das coisas, o símbolo é a comunicação, é a partilha, a existência social. O imaginário é coletivo, não só o individual (2011: 4).
}

\section{Espaços sociodinâmicos}

Este artigo compôs as premissas argumentativas do projeto de pesquisa em torno das relações socioculturais da cultura material de sociedades amazônicas na busca da compreensão dos processos sociopolíticos e econômicos ambientais. $\mathrm{O}$ foco nas artesanías em palha de tucumã delimita as análises teóricas e discursivas que permeiam a vida humana e biodiversa numa 
nova paisagem espraiada pela busca do desenvolvimento local, amparado na emergente discussão em torno da inclusão e equidade social.

A compreensão da mobilidade territorial dos grupos familiares das/ os artesãs/ãos carregando as práticas em seus múltiplos sentidos, cruzam com outras práticas numa reterritorialidade como constado no campo, numa hibridização cultural (LITTLE, 2012; GARCIA CANCLINI, 2006). Nesse sentido, destacando que "certas dinâmicas e práticas de organizações e movimentos não se inserem no sistema capitalista e não se subordinam a ele, não porque são resquícios do passado, mas sinais de futuro" (LEROY, 2012: 59).

Estudar as relações socioculturais dos/as artesãs/ãos do tecido em palha de tucumã permitiu visualizar a criação de lugares, tendo as artesanías como uma lente para as reflexões socioculturais. As análises da pesquisa com suporte na oralidade da memória coletiva possibilitaram compreender os processos que levaram a formação do território e da própria escolha que hoje abarca as artesanías. Mais do que tudo que as diferenças desses lugares demonstram que é possível uma existência em bases sustentáveis, e que a geração de conhecimento deve apoiar esses processos no compartilhamento com os povos que os vivenciam na organização social.

\section{Notas}

${ }^{1}$ Do espanhol, refere-se tanto a trabalhos manuais como intelectual resultante das elaborações humanas. Esse conceito é muito bem delineado pelo mexicano Octavio Paz (2012) em O uso e a contemplação, quando diz que a peça de artesanato

preserva as impressões digitais - reais ou metafóricas - do artesão que a criou. Essas impressões não são a assinatura do artista; elas não são um nome. Nem são uma marca registrada. Antes, são um signo: a cicatriz quase invisível que denota a irmandade original dos homens, e sua separação. Além de ser feito por mãos humanas, o artesanato também é feito para mãos humanas: não apenas podemos vê-lo, mas tocálo com nossos dedos

(http://revistaraiz.uol.com.br/portal/index.php?option=com_content\&task=view\& $\mathrm{id}=102 \&$ Itemid=116).

${ }^{2} \mathrm{Na}$ época que nasceu não havia registro sistemático de nascimento, portanto, não sabem ao certo sua idade, apesar de receber aposentadoria.

${ }^{3}$ Sobreprodutosdasociobiodiversidade: http://comunidades.mda.gov.br/portal/saf/arquivos/ view/sociobiodiversidade/PLANO_NACIONAL_DA_SOCIOBIODIVERSIDADE__ julho-2009.pdf) 
${ }^{4}$ São recursos naturais com que comumente os povos indígenas elaboram os utensílios da lida cotidiana da farinha e extrativismo: peneiras, tipitis, paneiros, cestos cargueiros, jamaxins, balaios, matapis, entre outros.

\section{Referências}

ADAMS, C. et. al. (Edits.) Sociedades caboclas amazônicas: modernidade e invisibilidade. São Paulo: Annablume, 2006.

AGASSIZ, Luiz \& AGASSIZ, Elizabeth Cary. Viagem Ao Brasil, 1855-1865. São Paulo: Editora da Universidade de São Paulo; Belo Horizonte: Livraria Itatiaia Editora Limitada, 1975, p. 157-214.

ALENCAR, E. F. Paisagens da memória: narrativa oral, paisagem e memória social no processo de construção da identidade. Teoria \& Pesquisa, volume XVI, n. ${ }^{\circ}$ 02, jul./dez, 2007, arquivo digital.

ALENCAR, E. Memórias de Mamirauá. Tefé-AM: Instituto de Desenvolvimento Sustentável Mamirauá, 2010.

APPADURAI, A. Introdução: mercadorias e a política de valor. In: APPADURAI, A. A vida social das coisas: a mercadoria sob uma perspectiva cultural. Trad. Agatha Bacelar. Niterói-RJ: Editora da Universidade Federal Fluminense, 2008. Disponível em http://www.4shared.com/office/ Dp4OEawe/APPADURAI_Arjun_-_A_Vida_Socia.html. Acesso em: 16 jun. 2012.

BARTH, F. Grupos étnicos e suas fronteiras. In: POUTIGNAT, P. Teorias da etnicidade. Seguido de Grupos étnicos e suas fronteiras de Fredrik Barth e Jocelyne Streiff-Fenart. Trad. Elcio Fernandes. São Paulo: Fundação Editora da Unesp, 1998.

BATES, H. W. (1820-1892). Um naturalista no rio Amazonas. Trad. Regina Régis Junqueira, apresentação Mário Guimarães Ferri. Belo Horizonte: Ed. Itatiaia; São Paulo: Ed. da Universidade de São Paul, 1979.

BENCHIMOL, S. Amazônia: formação social e cultural. 3. ${ }^{a}$ ed. Manaus: Editora Valer, 2009.

BUARQUE DE HOLLANDA, Bernardo; RIBEIRO, Rodrigo. Entrevista 
com Maurice Godelier. Revista Estudos Políticos, número 2, 2011. Disponível em http://revistaestudospoliticos.com/entrevista-com-maurice-godelier-porbernardo-buarque-e-rodrigo-ribeiro/. Acesso em: 7 ago. 2012.

CASTRO, E. Território, biodiversidade e saberes de populações tradicionais. Papers do Naea, n. ${ }^{\circ}$ 092, Belém: UFPA, 1998, 19.

CARDOSO DE OLIVEIRA, Roberto. O trabalho do antropólogo: olhar, ouvir e escrever. In: CARDOSO DE OLIVEIRA, R. O trabalho do antropólogo.

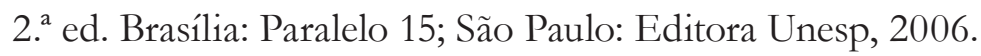

CARVALHO, L. (pesquisa e texto). Trançados do Arapiuns. Rio de Janeiro: Iphan, CNFCP, 2004.

CEAPS (Centro de Estudos Avançados em Promoção Social e Ambiental) / PSA (Projeto Saúde e Alegria) et. al. Terra indigena do Maró. Santarém: Prazer em Conhecer / Amazônia Vive, 2011.

- Uma cartografia da memória: mapeamento participativo socioambiental, Assentamento Agroextrativista do Lago Grande. Santarém, 2007.

CLIFFORD, J. A experiência etnográfica: antropologia e literatura no século XX. José Reinaldo Santos Gonçalves (Org.). Rio de Janeiro: Editora UFRJ, 1998.

DANIEL, J. (1722-1776). Tesouro descoberto no máximo rio Amaz̧onas. V. 1. Rio de Janeiro: Contraponto, 2004.

ESTERCI, N. \& SCHWEICKARDT, K. H. S. C. Territórios amazônicos de reforma agrária e de conservação da natureza. In: Boletim Museu Emilio Goeldi, v. 5 , n. ${ }^{\circ}$, Belém, 2010.

FREIRE, P. Pedagogia da autonomia. 31. ${ }^{\text {a }}$ ed. São Paulo: Terra e Paz, 1996.

GALÚCIO, Dorenilce Maria R.. Amazônia: pescadores contam histórias. Manaus: Ibama / ProVárzea (coleção Retrato Regional), 2004.

GARCÍA CANCLINI, N. Culturas híbridas: estratégias para entrar e sair da modernidade. Trad. Heloísa Pezza Cintrão, Ana Regina Lessa. Trad. da introdução Gênese Andrade. 4. ${ }^{a}$ ed. 1. ${ }^{a}$ reimp. São Paulo: Editora Universidade de São Paulo, 2006.

GONÇALVES, J. R. S. Antropologia dos objetos: coleções, museus e patrimônios. Rio de Janeiro, 2007. 
GEERTZ, C. Uma descrição densa: por uma teoria interpretativa da cultura. In: A interpretação da cultura. Rio de Janeiro: Editora Guanabara Koogan S.A, 1989.

GRUPO TÉCNICO COBRA-GRANDE. Relatório Circunstanciado de Identificação e Delimitação da Terra Indígena Cobra-Grande. Coordenação Leandro Mahalem de Lima. Santarém, Pará, 2009.

HALBWACHS, M. A memória coletiva. Trad. de Beatriz Sidou. São Paulo: Centauro, 2006.

HANNERZ, U. Fluxos, fronteiras, hídridos: palavras-chave da antropologia transnacional. Mana, volume 3, n. ${ }^{\circ}$ 1, 1997. Disponível em http: //www.scielo. br/scielo.php?script=sci_arttext\&pid=S0104-93131997000100001. Acesso em: 3 jul. 2012.

HÉBETTE, J. \& MOREIRA, E. Situação social das áreas rurais amazônicas. In: HÉBETTE, Jean. Cruqando a fronteira: 30 anos de estudo do campesinato na Amazônia. Vol. IV. Belém: EDUFPA, 2004.

INGLÊS DE SOUSA, H. M. O coronel Sangrado (Cenas da Vida do Amaronas). Belém: Universidade Federal do Pará; Santos-SP: publicado em 1877, 1968.

ISAAC, V. J. et. al. Atividades pesqueiras no Lago Grande de Curuai: Região Médio Amazonas. Manaus: Edua / ProVárzea / Ibama, 2003.

JURANDIR, D. Chove nos campos de Cachoeira. 4. a ed. Belém: Cejup, 1995.

KOPYTOFF, I. A biografia cultural das coisas: a mercantilização como processo. In: APPADURAI, A. A vida social das coisas: a mercadoria sob uma perspectiva cultural. Trad. Agatha Bacelar. Niterói-RJ: Editora da Universidade Federal Fluminense, 2008. Disponível em http://www.4shared.com/office/ Dp4OEawe/APPADURAI_Arjun_-_A_Vida_Socia.html. Acesso em: 16 jun. 2012.

KRUCKEN, L. Design e território: valorização de identidades e produtos locais. São Paulo: Studio Nobel, 2009, 20.

LEROY, J. P. Contra a mercantilização e a privatização da vida e da natureza, os Bens Comuns. Proposta, ano 36, n. ${ }^{\circ}$ 125, 2012.

LITTLE, P. E. Espaço, memória e migração: por uma teoria de reterritorialização. 
Disponível em http://seer.bce.unb.br/index.php/textos/article/ viewFile/5757/4764. Acesso em: 23 ago. 2012.

MACHADO, et. al. Fazendo educação ambiental. Santarém: Instituto de Pesquisa Ambiental na Amazônia, 2001.

MACHADO, L. O. Urbanização e mercado de trabalho. Grupo de Pesquisa Retis, 2002.

MANZINI, E. Design para a inovação social e sustentabilidade, comunidades criativas, organizaçôes colaborativas e novas redes projetuais. Rio de Janeiro: E-papers, 2008.

NEDERVEEN PIETERSE, J. Globalization as hibridization. Working Paper Series, n.o 152. 1993. Disponível em http://repub.eur.nl/res/pub/18857/wp152. pdf. Acesso em: 3 jul. 2012.

PAZ, O. O uso e a contemplação. Trad. Alexandre Bandeira, 2011. Disponível em http://revistaraiz.uol.com.br/portal/index.php?option=com_content\&task $=\mathrm{v}$ iew\&id=102\&Itemid=116. Acesso em: 1. ${ }^{\circ}$ jun. 2012.

SHANLEY, P. \& MEDINA, G. Frutíferas e plantas úteis na vida amąônica. Belém: Cifor / Imazon, 2005.

SCHWEICKARDT, K. H. S. C. As diferentes faces do Estado do Amazonas: etnografia dos processos de criação e implantação da Resex Médio Juruá e da RDS Uacari no médio rio Juruá. Rio de Janeiro: UFRJ, 2010.

THOMSON, A. Histórias (co)movedoras: história oral e estudos de migração. Revista Brasileira de História, volume 22, n. ${ }^{\circ}$ 44. São Paulo, 2002. Disponível em http://www.scielo.br/scielo.php?pid=S010201882002000200005\&script=sci_arttext. Acesso em: 27 ago. 2012.

TOCANTINS, L. O rio comanda a vida: uma interpretação da Amazônia. Rio de Janeiro: Gráfica Record Editora, 1968.

WAGLEY, C. Uma comunidade amarônica: estudo do homem nos trópicos. Trad. Clotilde da Silva Costa. 3. ${ }^{a}$ ed. Belo Horizonte: Editora Itatiaia; São Paulo: Editora da Universidade de São Paulo, 1988.

WILLIAMS, Raymond. Política do modernismo: contra os novos conformistas. Trad. André Glaser. São Paulo: Editora Unesp, 2011. 